\title{
Quantitative ${ }^{1} \mathrm{H}$ NMR: Development and Potential of a
}

\section{Method for Natural Products Analysis ${ }^{\perp}$}

Guido F. Pauli, ${ }^{\dagger \ddagger}$ Birgit U. Jaki, ${ }^{\ddagger}$ and David C. Lankin ${ }^{\dagger}$

Department of Medicinal Chemistry and Pharmacognosy and ${ }^{\ddagger}$ Institute for Tuberculosis

Research, College of Pharmacy, University of Illinois at Chicago, Chicago, IL 60612

Supplementary Data

* To whom correspondence should be addressed. Tel (312) 355-1949. Fax (312)355-2693. E-mail: gfp@uic.edu.

${ }^{\perp}$ Dedicated to Dr. Nikolaus H. Fischer on his retirement, with best wishes for the achievement of another level of academic freedom.

${ }^{\dagger}$ Department of Medicinal Chemistry and Pharmacognosy

${ }^{\ddagger}$ Institute for Tuberculosis Research 


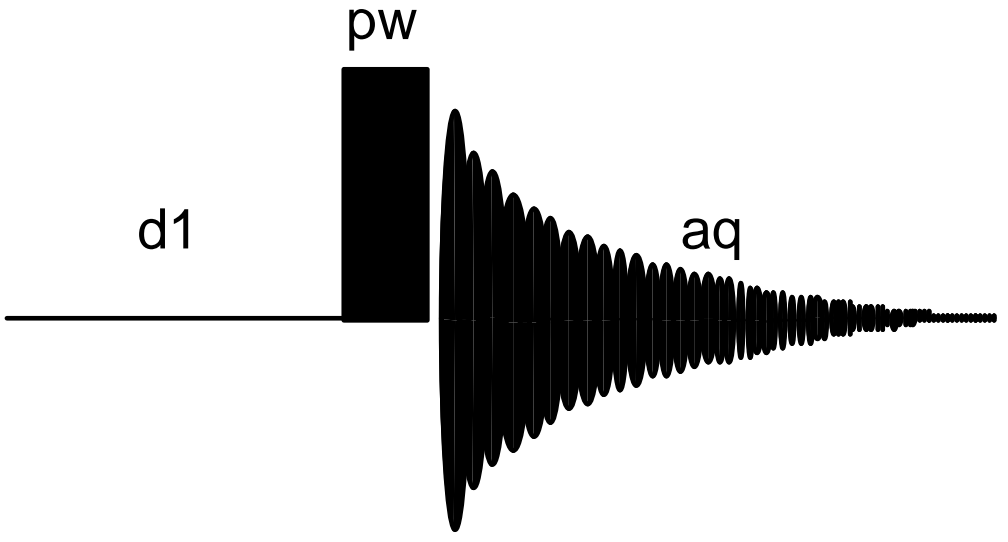

Figure S1. Standard pulse profile for a 1D NMR experiment 


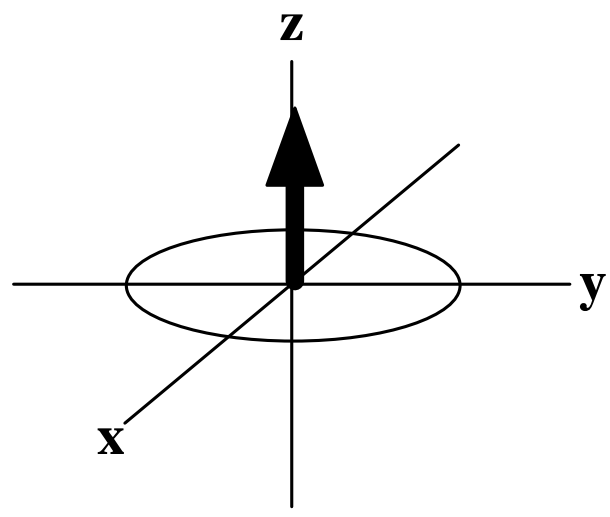

A

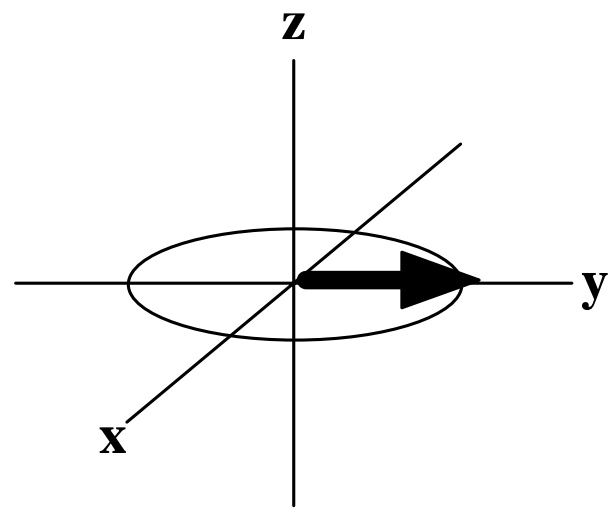

B

Figure S2. Magnetization before (A) and immediately after (B) a $90^{\circ}{ }_{x}$ pulse 

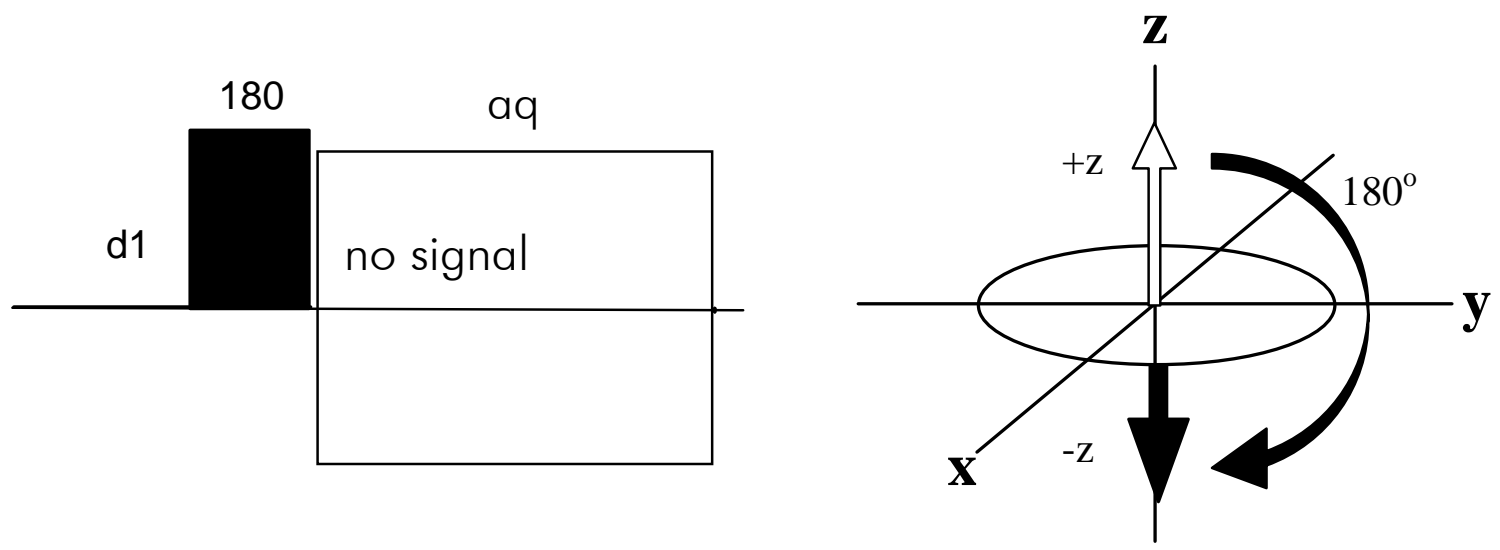

Figure S3. A $180^{\circ}$ inversion pulse converts the $+\mathrm{z}$ magnetization into $-\mathrm{z}$ magnetization and leaves no signal to acquire during $a q$ 


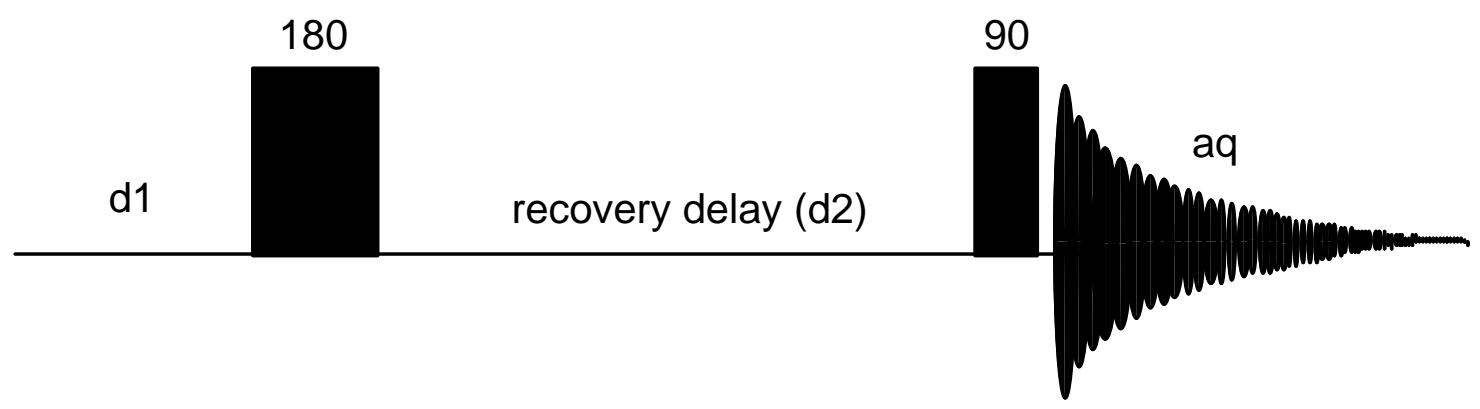

Figure S4. Inversion-recovery $\left(T_{1}\right)$ pulse sequence 